\title{
Ball Milling Pretreatment of Bagasse for Ethanol Production by Enzymatic Saccharification and Fermentation
}

\author{
M. S. Jamal ${ }^{a *}$, S.M. A. Sujana, M. Y. Miah', S. K. Banik ${ }^{a}$, S. U. Ahmed ${ }^{b}$ and B. Feroza ${ }^{b}$ \\ ${ }^{a}$ Institute of Fuel Research and Development (IFRD) and ${ }^{b}$ Institute of Food Science and Technology (IFST), \\ Bangladesh Council of Scientific and Industrial Research (BCSIR), Dhaka-1205, Bangladesh.
}

\begin{abstract}
Enzymatic saccharification (Hydrolysis) is one of the technologies to hydrolyze lignocellulosic biomass. In this study, Bangladeshi bagasse is used as feedstock for enzymatic saccharification and ethanol fermentation. Cutter mill and Mechano-chemical treatment (Ball mill) are used for pretreatment. The main objective of this study is to investigate the effect of substrate concentration, pretreatment time and enzyme concentration to enzymatic hydrolysis and ethanol fermentation. The yield of glucose from cellulose is decreased with increasing substrate concentration from $5 \%$ to $15 \%$, but the total amount of glucose is increased with increasing substrate concentration. Sample with long pretreatment time hydrolysis easily. Ball milling pretreatment of 1 hour is the most effective on enzymatic hydrolysis which gives better sugar yield than others. Enzyme loading has significant effect on enzymatic hydrolysis. Yeast Saccharomyces cerevisiae was used to converts $\mathrm{C}_{6}$ sugar into ethanol and incubated at $30^{\circ} \mathrm{C}$ for 96 hours. Almost all fermentable sugar converted into ethanol within 24 hours.
\end{abstract}

Key words : Enzymatic saccharification, Lignocellulosic biomass, Ethanol, Fermentation, Mechano-chemical treatment.

\section{Introduction}

Production of ethanol from renewable lignocellulosic materials has been extensively studied in the last decades (Demirbas, A. 2005, Eriksson et al. 2002, Kim et al. 2008, Sun. and Cheng, 2002). The major components in lignocellulosic biomass are cellulose, hemicellulose, and lignin. The primary technical and economic challenge for the production of biofuels from lignocellulosic biomass mainly depends on converting the complex cellulosic and hemicellulosic carbohydrates into fermentable sugars which then can be fermented to biofuels by various microorganisms. Lignocellulosic biomass is one potential resource for the production of fuels such as ethanol, and the bioconversion of lignocellulosic biomass to ethanol is a multi-step process consisting of pretreatment, enzymatic hydrolysis and ethanol fermentation. Among these steps, pretreatment is particularly crucial in view of the recalcitrance of lignocellulosic structure to enzymatic hydrolysis, i.e. the lignin seal and the hemicellulose sheath of cellulose and the crystallinity of cellulose itself, and often dominates the cost of the whole conversion process (Mosie et al. 2005, Wyman et al., 2005). In general, pretreatment of lignocellulosic biomass is required in the bioconversion process involving enzymatic hydrolysis and

\footnotetext{
* Corresponding author: E-mail: msjdubd@gmail.com
}

fermentation. The purpose of the pretreatment is to separate lignin and hemicellulose from cellulose, reduce cellulose crystallinity, and increase the porosity of the lignocellulosic materials so that cellulose hydrolysis can be significantly improved. Many pretreatment methods have been reported and several detailed review papers have been published (Galbe. and Zacchi, 2007, Sun. and Cheng, 2002, Mosie et al. 2005, Taherzadeh and Karimi, 2008).

The pretreatment processes involve employing high temperature, pressure, acids or bases, and organic solvents. Most of pretreatment methods have their drawbacks in large scale application. For example, the dilute acid process generates toxic byproducts, such as furfural and aldehydes, which not only significantly reduces the sugar yield but also toxic for enzymatic hydrolysis and biofuels fermentation. Steam explosion, operated at high temperature and pressure to achieve fibrillation, requires costly capital investment for equipments. Recently, the pretreatment involves using cellulose dissolution reagents, such as ionic liquids (Dadi et al. 2006), concentrated phosphoric acid (81\%) (Wei et al. 1996; Zhang et al. 2006, 2007), NaOH/urea solutions at cold tem- 
perature (Zhao et al. 2008) have been demonstrated to be very effective for enhancing cellulose hydrolysis. The operation conditions for these pretreatments are much milder $\left(<100^{\circ} \mathrm{C}\right.$ and atmosphere pressure) as compared to the conventional pretreatment methods.

In this paper, sugarcane bagasse was used as the model lignocellulosic material to be pretreated by ball milling at various conditions. Justifications of ball mill (BM) pretreatment were effective for a decrease in the cellulose crystallinity of bagasse and improve the enzyme digestibility (Teramoto et. al. 2008, Mais et al. 2002). Ball mill treatment disrupts cellulose-hemicellulose-lignin network in the cell wall by milling energy and is known to promote the enzymatic hydrolysis of bagasse. This work focuses on the parameters that effect the conversion of cellulose to ethanol followed by glucose production. The main objective was to develop an approach that would enable us to better understand the relationship between the variables (Substrate concentration, milling time, enzyme concentration) and fermentation condition to obtain the optimum condition for ethanol production. The morphology and structure of the bagasse regenerated from pretreatment mixture were studied.

\section{Materials and Methods}

\section{Sugarcane Bagasse}

Sugarcane bagasse used in this work was supplied from the Rajshahi sugar mill (a renounce industry of BSFIC), Rajshahi, Bangladesh in December 2008.

\section{Cutter Mill}

Dried bagasse was milled by cutter mill (Fretsch, Germany) into $2 \mathrm{~mm}$ and $0.25 \mathrm{~mm}$ size $2.0 \mathrm{~mm}$ size was used for ball milling pretreatment and $0.25 \mathrm{~mm}$ size was used for acid hydrolysis for the determination of composition of bagasse.

\section{Ball Mill}

Ball milling was performed using the TI-300 system, (CMT Co., Saitama, Japan). $2 \mathrm{~mm}$ size air dried bagasse (50 g) was added to a pod containing 90 stainless steel balls (Diameter, $2 \mathrm{~cm})$. Milling was carried out for a total time 10-120 min at room temperature.

\section{Analytical Method}

The composition of raw material was analyzed according to the analytical procedure of the National Renewable Energy
Laboratory (NREL) (Sluiter et al. 2006). The ash content was determined by placing $1.5 \mathrm{~g}$ sample in a muffle furnace at $600^{\circ} \mathrm{C}$ for 24 hours, cooling in a desicator, and then weighing for ash. Sugars and degradation products in the liquid fraction samples were analyzed by following the NREL procedure (Sluiter et al. 2005). Monomeric sugars in the liquid fraction were analyzed by HPLC (Jasco, Japan) using a Bio rad Aminex HPX-87P column $(300 \times 7.8 \mathrm{~mm})$ equipped with a refractive index detector (Sluiter et al. 2005). The mobile phase was degassed deionized water with a flow rate of 1.0 $\mathrm{ml} / \mathrm{min}$. The column temperature was $80^{\circ} \mathrm{C}$. Total sugars consisting of monomeric and oligomeric sugars in the liquid fraction were analyzed by sulfuric acid hydrolysis method followed by HPLC determination (Sluiter et al. 2005). Degradation products in the liquid fraction were analyzed by HPLC using a Biorad Aminex HPX-87H column $(300 \times 7.8$ $\mathrm{mm}$ ) equipped with a refractive index detector (Sluiter et al. 2005). The mobile phase was $0.01 \mathrm{~N}$ sulfuric acid with a flow rate of $0.6 \mathrm{ml} / \mathrm{min}$. The column temperature was $60^{\circ} \mathrm{C}$. Analysis was carried out in duplicate, and results are expressed as the mean values. Relative standard deviations in all cases were within $5 \% . \mathrm{pH}$ in the liquid fraction was measured by a $\mathrm{pH}$ meter at room temperature.

\section{Yeast inoculum preparation}

Yeast strain Saccharomyces cerevisiae known as $\mathrm{IR}_{2}$ (Originally isolated by Kuriyama (AIST) et al. Journal of Fermentation Technology vol.63 pp159-165(1985)) was used in all fermentation assays to converts $\mathrm{C}_{6}$ sugar into ethanol. Experiment was performed in a $250 \mathrm{ml}$ Erlenmeyer flask containing $60 \mathrm{ml}$ of culture medium containing $0.1 \%$ $(\mathrm{w} / \mathrm{v})$ yeast extract $0.2 \%(\mathrm{w} / \mathrm{v})$ peptone and supplemented with $2 \%(\mathrm{w} / \mathrm{v})$ glucose. Cultivation was carried out at $30^{\circ} \mathrm{C}$.

\section{Separated Hydrolysis and Fermentation (SHF)}

Hydrolysis was performed in a $40 \mathrm{ml}$ vial magnetically stirred with a reaction volume of $20 \mathrm{ml}$. Different substrate concentration, milling time and enzyme loadings (Acremonium cellulase, Optimash BG) were used to determine the optimum condition. Hydrolysis was carried out in $50 \mathrm{mM}$ acetate buffer ( $\mathrm{pH} 5.0$ ) at $50^{\circ} \mathrm{C}$ for 72 hours. Upon completion of hydrolysis, $2 \mathrm{ml}$ of YPD preculture of Saccharomyces cerevisiae $\left(\mathrm{IR}_{2}\right)$ was inoculated and fermentation was carried out at $30^{\circ} \mathrm{C}$ for 72 hours. For comparison, the solid fraction together with about $1 / 4$ strength of the hydrolysate from the same pretreatment was also tested for 
SHF. $\mathrm{pH}$ was checked and adjusted to the same value for the two cases before and after saccharification. Samples from hydrolysis and fermentation were analyzed by HPLC using a Bio rad Aminex HPX-87P column under the same conditions as above.

\section{Calculation of Sugar yield}

All sugar yields in this paper are mentioned by compare with acid hydrolysis which is termed as theoretical yield of sugar.

Theoretical yield $=\frac{\text { Experimental yield }}{\text { Total yield (Yield of acid hydrolysis) }} \times 100$

\section{Result and Discussion}

\section{Raw Materials}

The composition of bagasse used in this work was determined by acid hydrolysis and shown in the table below:

\begin{tabular}{l|c}
\hline Name of sugar & Composition, \% \\
\hline Glucan & 44.22 \\
Xylan & 29.52 \\
Galactan & 1.37 \\
Arabinan & 2.81 \\
Mannan & 1.80 \\
Ash & 4.13 \\
\hline
\end{tabular}

The content of most carbohydrates such as Glucan and Xylan were comparable those of corn stover, whereas the content of Arabinan and Galactan were less than those of corn stover (Wyman et al. 2005). It is noticed that the ash content was comparable with many kind of lignocellulosic biomass especially woody biomass (Bobleter, 1994).

\section{Enzymatic Hydrolysis}

\section{Effect of substrate concentration on the digestibility of pretreated bagasse}

The Effect of substrate concentration on the digestibility of pretreated bagasse is shown in Figure 1. To investigate optimum substrate concentration on enzymatic hydrolysis, same pretreated (MC 1 hour) 5\%,10\% and 15\% substrate were hydrolyzed in the same enzyme concentration (4 FPU/g) for $72 \mathrm{hrs}$. The digestibility of Glucan and Xylan were estimated and the yield of Glucan is decreased from $87 \%$ to $65 \%$ and xylan from $92 \%$ to $66 \%$ with increasing substrate con- centration from $5 \%$ to $15 \%$ but the total amount of sugar is increased. Percentage of yield at higher substrate concentration is decreased may be due to low enzyme activity at high sugar concentration. Considering yield and total amount of glucose, $10 \%$ substrate may be the optimum substrate concentration that has been used for next all experiment. The advantage of using a high concentration substrate are that the capital equipment cost for hydrolysis can be reduced and rich sugar syrups can be produced and consequently the cost of ethanol fermentation and distillation are reduced (Tassinari et al., 1980).

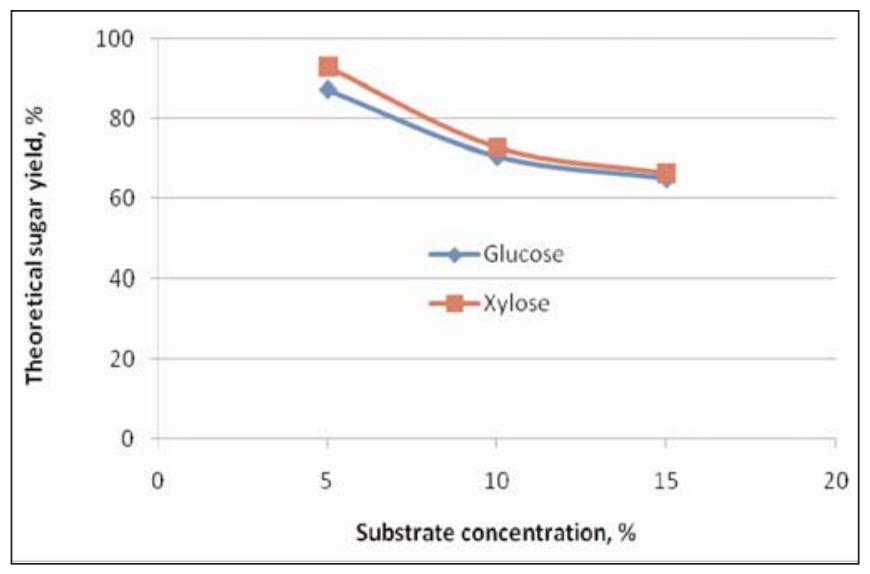

Fig. 1: Effect of substrate concentration on the digestibility of pretreated bagasse at enzyme concetration 4 FPU/g

Effect of milling time on the digestibility of pretreated bagasse

The Effect of pretreatment condition (milling time) on the digestibility of bagasse is shown in Figure 2. For the investigation of pretreatment condition on enzymatic hydrolysis, Raw bagasse (2mm), ball milled for 10min (MC $10 \mathrm{~min}$ ), 30min (MC $30 \mathrm{~min}$ ), 1 hour (MC $60 \mathrm{~min}$ ) and 2 hours (MC $120 \mathrm{~min}$ ) were hydrolyzed in the same enzyme concentration (4FPU/g) for $72 \mathrm{hrs}$. Ball milling pretreatment for 1 hour (MC $60 \mathrm{Min}$ ) is the most effective on enzymatic hydrolysis than others. $70.5 \%$ of theoretical yield of Glucan and $73 \%$ of theoretical yield of Xylan was obtained for MC 60 Min. Glucan is almost $2.5 \%$ and Xylan is $5.5 \%$ less than that of MC 120 Min. The yield of other pretreated substrates is lower than that of MC 60 Min. Glucose and Xylose hydrolysis yields at optimum condition for ball mill treated bagasse was $78.7 \%$ and $72.1 \%$ (Ayla et al., 2010). There glucose yield is little bit low may be due to using vibrating type ball mill rather than planetary type pulverisette. 


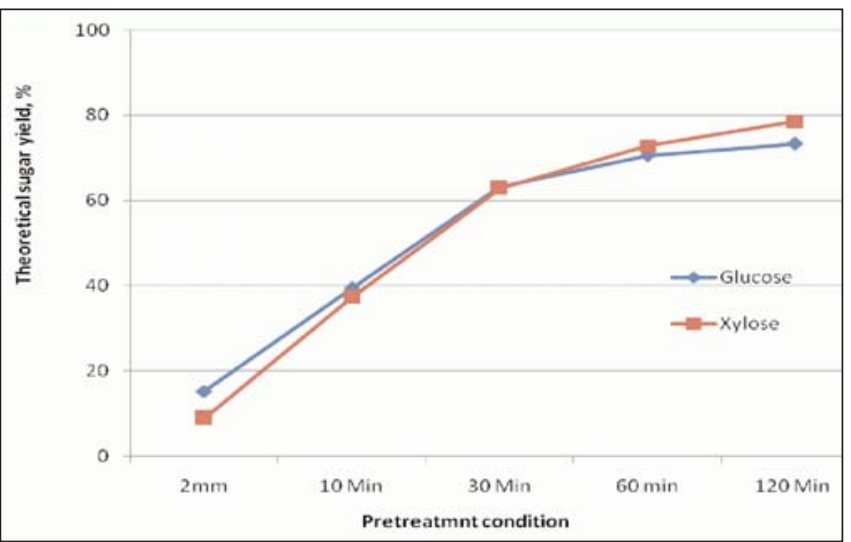

Fig. 2: Effect of milling time on the digestibility of pretreated bagasse sample at enzyme concentration 4 FPU/g substrate

Effect of enzyme loading on the digestibility of pretreated bagasse

In order to determine the effect of enzyme concentration on enzymatic saccharification of bagasse, MC 60 min sample were hydrolyzed for $72 \mathrm{hrs}$ with enzyme dose (Acremonium cellulase, Optimash BG) 2, 4, 8, 20 and 40 FPU/g of substrate and shown in Figure 3. It was found that the sugar yield is increased with increasing enzyme loading and in enzyme dose 4FPU/g of substrate; the sugar yield is $70.5 \%$ which is closed to yield of 8FPU/g and $12 \mathrm{FPU} / \mathrm{g}$ and $9 \%$, $13 \%$ less than that of $20 \mathrm{FPU} / \mathrm{g}$ and $40 \mathrm{FPU} / \mathrm{g}$ respectively. On the other hand Xylan yield is $73 \%$ which is $4 \%$ less than that of 40FPU/g. It need to be mentioned here, saccharification was possible with very low amount of cellulose (4FPU/g substrate) which means ball milling is effective pretreatment for reducing enzyme load as well as saccharification cost.

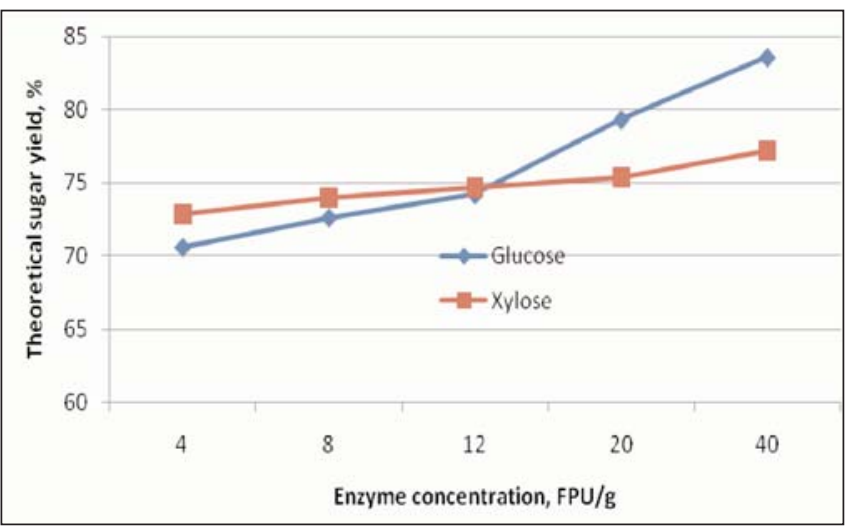

Fig. 3: Effect of enzyme loading on the digestibility of pretreated bagasse

\section{Fermentation}

For glucose fermentation, hydrolysate from $10 \%$ substrate, $\mathrm{MC} 1 \mathrm{hr}$ and enzyme concentration 4FPU/g and $40 \mathrm{FPU} / \mathrm{g}$ of substrate were used that contain $2.08 \%$ and $2.43 \%$ glucose respectively. Yeast Saccharomyces cerevisiae was used to converts $\mathrm{C}_{6}$ sugar into ethanol and incubated at $30^{\circ} \mathrm{C}$ for 48 hours. It was found that almost all fermentable sugar converted into ethanol within 24 hours and after 48 hrs fermentation yields were $0.18 \mathrm{~L} / \mathrm{Kg}$ Sub and $0.20 \mathrm{~L} / \mathrm{Kg}$ Sub for 4 $\mathrm{FPU} / \mathrm{g}$ and $40 \mathrm{FPU} / \mathrm{g}$ of substrate respectively.

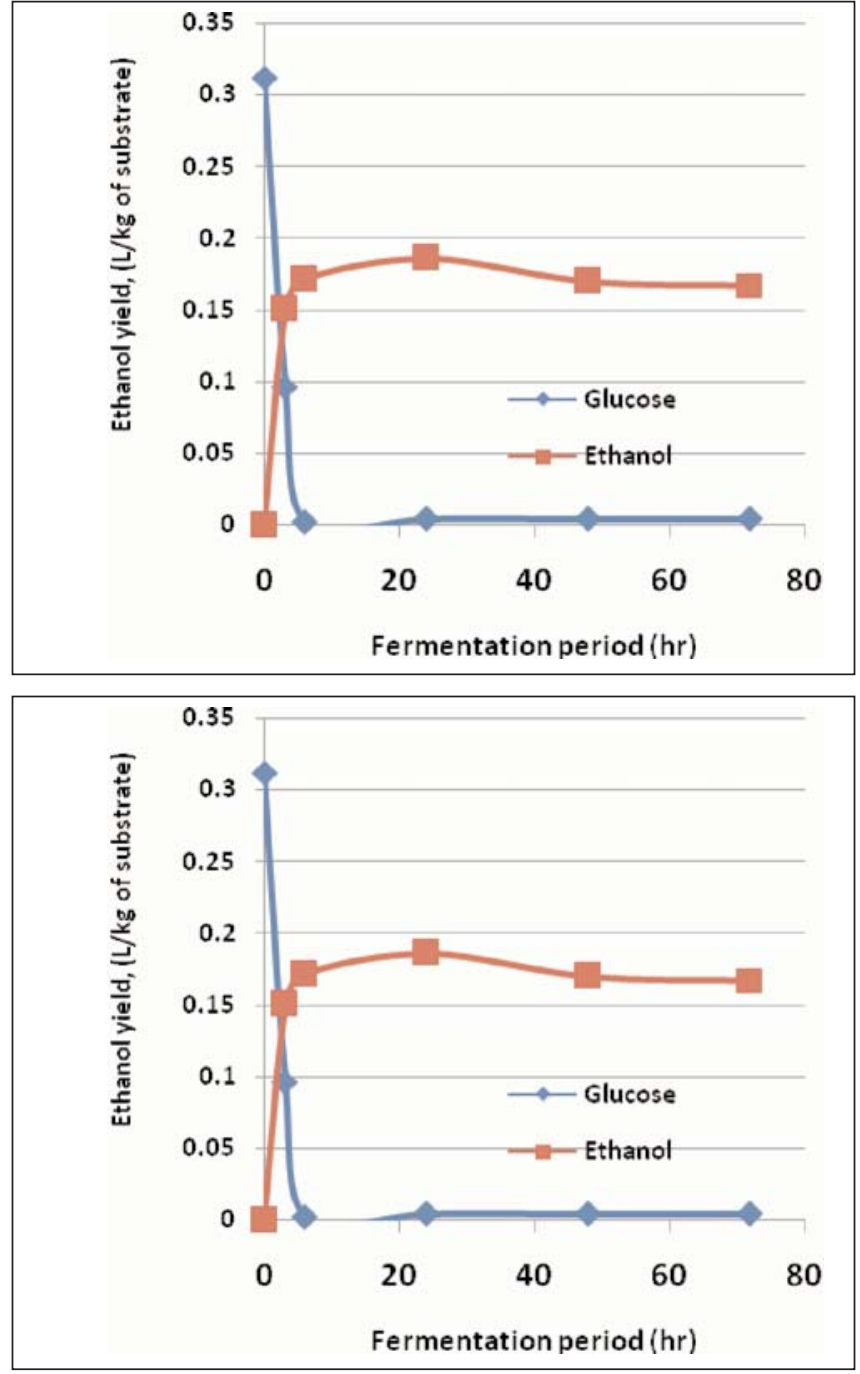

Fig. 4: Fermentation yield of hydrolysate at enzyme concentration (a) $4 \mathrm{FPU} / \mathrm{g}$ and (b) $40 \mathrm{FPU} / \mathrm{g}$ of substrate 


\section{Morphology of HCW pretreated Bagasse}

The SEM micrographs of bagasse untreated and treated under different conditions are presented in Figure 5. The raw materials displayed irregular and compact surface structure 5(a) and pretreatment destroyed cellulosic structure significantly and higher severity resulting in case of longer pretreatment time 5(b) \& 5(c). The structure of cellulose after pretreatment effectively disintegrated when attack by cellulase 5(d).

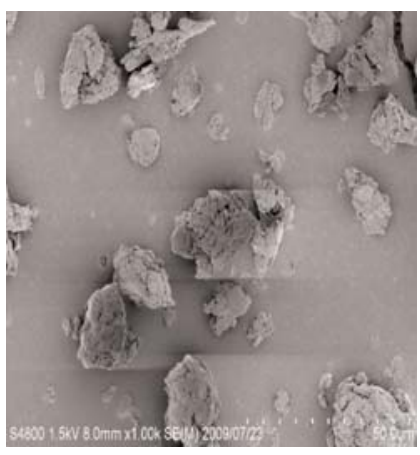

5 (a) Raw Bagasse

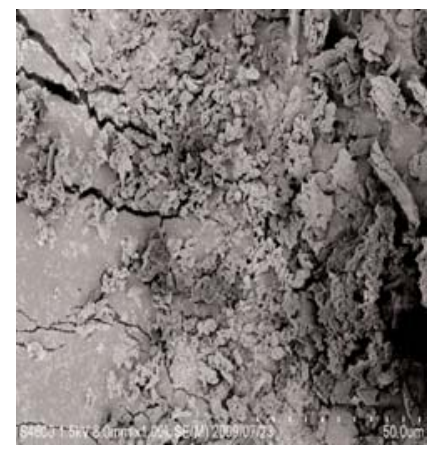

5 (b) Ball Mill 30 min

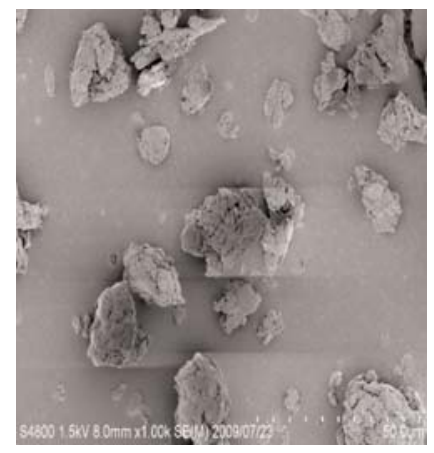

5 (c) Ball Mill $60 \mathrm{mi}$

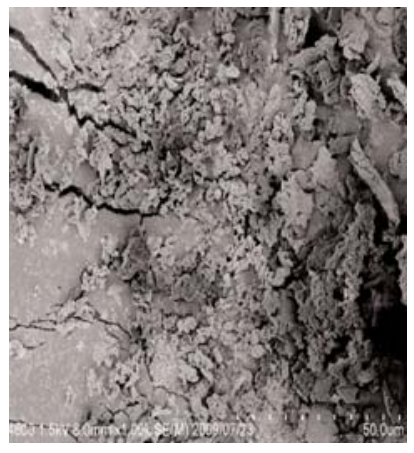

5 (d) Residue after Saccharification

Fig. 5: SEM photograph of Treated and Untreated Sample

\section{Conclusion}

The sugars composition bagasse sample contains $44.22 \%$ Glucan and 29.54\% Xylan 1.37\% Galactan, 2.81\% Arabinan, 1.8\% Mannan, 2.55\% Moisture and 4.13\% Ash.

Pretreatment time has effect not only to enzymatic saccharification, but also for percentage of substrate concentration and enzyme loading. Sample with long pretreatment time is easier for hydrolysis by enzyme even used low enzyme load, i.e. MC 1 hours pretreatment of bagasse hydrolyze with 4 FPU/g given $70.5 \%$ of glucose and $73 \%$ Xylose theoretically. Enzyme load has more effective with substrate that pretreated with short pretreatment time which the sugar yield will increase with higher enzyme loads. For long pretreat ment time 30 min to 2 hours enzyme load has slightly effect with their hydrolysis. Hydrolyzate of $10 \%$ substrate, MC 1 $\mathrm{hr}$ and enzyme concentration 4FPU/g and $40 \mathrm{FPU} / \mathrm{g}$ of substrate were used for fermentation that contain $2.8 \%$ and $2.4 \%$ glucose respectively. Yeast Saccharomyces cerevisiae was used to converts C6 sugar into ethanol and incubated at 300C for 48 hours. It was found that almost all fermentable glucose is converted into ethanol within 24 hours and yields tion Agency (JICA) under the research on Biomass Technology programme.

\section{References}

Ayla S. D. S., Inoue H., Endo. T., Yano. S. and Bon E. P. S. (2010). Milling pretreatment of sugarcane bagasse and straw for enzymatic hydrolysis and ethanol fermentation. Article in press, Bioresource Technology,

Bobleter O. (1994). Hydrothermal degradation of polymer derive from plants. Prog. Polym. Sci 19: 797-841

Dadi A. P., Varanasi S. and Schall C. A. (2006). Enhancement of cellulose saccharification kinetics using an ionic liquid pretreatment step. Biotechnology and Bioengineering. 95: 904-910.

Demirbas A. (2005). Bioethanol from Cellulosic Materials:A Renewable Motor Fuel from Biomass. Energy Sources, 21: 327-337.

Eriksson T., Karlsson J. and Tjerneld F. (2002). A model explaining declining rate in hydrolysis of lignocellu- 
lose substrates with cellobiohydrolase I (cel7A) and endoglucanase I (cel7B) of Trichoderma reesei. Appl Biochem Biotechnol 101: 41-60.

Galbe M. and Zacchi G. (2007). Pretreatment of lignocellulosic materials for efficient bioethanol production. Adv. Biochem. Eng./Biotechnol. 108: 41-65.

Kim T. H., Taylor F. and Hicks K. B. (2008). Bioethanol production from barley hull using SAA (soaking in aqueous ammonia) pretreatment. Bioresource Technology 99: 5694-5702

Mais U., Esteghlalian A. R., Saddler J. N. and Mansfield S. D. (2002). Enhancing the enzymatic hydrolysis of cellulosic materials using simultaneous ball milling. Applied Biochemistry and Biotechnolog. 98-100: 815832.

Mosier N., Wyman C., Dale B., Elander R., Lee Y. Y., Holtzapple M. and Ladisch M. (2005). Features of promising technologies for pretreatment of lignocellulosic biomass, Bioresource Technol. 96: 673-686.

Sluiter A., Hames B., Ruiz R., Scarlata C., Sluiter J., Templeton D. and Crocker D. (2006). Determination of structural carbohydrates and lignin in biomass, laboratory analytical procedure, National Renewable Energy Laboratory, Golden, CO.

Sluiter A., Hames B., Ruiz R., Scarlata C., Sluiter J. and Templeton D. (2005). Determination of Sugars, Byproducts, and Degradation Products in Liquid Fraction Process Samples, Laboratory Analytical Procedure, National Renewable Energy Laboratory, Golden, CO.

Sun Y. and Cheng J. (2002). Hydrolysis of lignocellulosic materials for ethanol production: a review. Bioresource Technol. 83:1-11

Taherzadeh M. J. and Karimi K. (2008). Pretreatment of Lignocellulosic Wastes to Improve Ethanol and Biogas Production: A Review. Int. J. Mol. Sci. 9:1621-1651.

Tassinari T, Macy C., Spano L. and Ryu DDY. (1980). Energy requirements and process design considerations in compresss milling pretreatment of cellulose waste for enzymatic hydrolysis, Biotechnology and Bioenergy, 22: 689-1705.
Teramoto Y., Tanaka N., Lee S. H. and Endo T. (2008). Pretreatment of Eucalyptus Wood Chips for Enzymatic Saccharification Using Combined Sulfuric Acid-Free Ethanol Cooking and Ball Milling. Biotechnology and Bioengineering, 99: 75-85,

Wei S., Kumar V. and Banker G. S. (1996). Phosphoric acid mediated depolymerization and decrystallization of cellulose: preparation of low crystallinity cellulose - a new pharmaceutical excipient. International Journal of Pharmaceutics 142: 175-181.

Wyman C. E., Dale B. E., Elander R. T., Holtzapple M., Ladisch M. R. and Lee Y. Y. (2005). Coordinated development of leading biomass pretreatment technologies. Bioresource Technol. 96: 1959-1966.

Zhang Y. H. P., Cui J., Lynd L. R. and Kuang L. R. (2006). A transition from cellulose swelling to cellulose dissolution by o-phosphoric acid: evidence from enzymatic hydrolysis and supramolecular structure. Biomacromolecules. 7: 644-648.

Zhang Y. H. P., Ding S. Y., Mielenz J. R., Cui J. B., Elander R. T., Laser M., Himmel M. E., McMillan J. R. and Lynd L. R. (2007). Fractionating recalcitrant lignocellulose at modest reaction conditions. Biotechnology and Bioengineering. 97: 214-223.

Zhao Y., Wang Y., Zhu J. Y., Ragauskas A. and Deng Y. (2008). Enhanced enzymatic hydrolysis of spruce by alkaline pretreatment at low temperature. Biotechnology and Bioengineering. 99: 1320-1328.

Received: April 20, 2010;

Accepted : December 27, 2010 